\title{
Gambaran Klinis dan Endoskopi Saluran Cerna Bagian Atas Pasien Dispepsia di Bagian RSUP Dr. M. Djamil Padang
}

\author{
Citra Yuriana Putri ${ }^{1}$, Arnelis $^{2}$, Asterina $^{3}$
}

\begin{abstract}
Abstrak
Dispepsia ialah suatu sindrom yang terdiri dari nyeri atau rasa tidak nyaman di ulu hati, kembung, mual, muntah, sendawa, rasa cepat kenyang, perut rasa penuh/begah. Salah satu alat diagnostik untuk dispepsia adalah endoskopi. Alat ini dapat menentukan jenis lesi dan lokasi lesi pada saluran cerna atas pasien dispepsia. Tujuan penelitian ini adalah mementukan frekuensi keluhan, derajat keluhan, insiden pasien dispepsia yang mengalami tanda bahaya berdasarkan jenis kelamin, faktor risiko dispepsia, diagnosis endoskopi dan lokasi lesi saluran cerna atas pasien dispepsia. Desain penelitian ini adalah deskriptif observasional. Subjek penelitian terdiri dari 54 orang pasien dispepsia yang dilakukan pemeriksaan esofagogastroduodenoskopi (EGD) di RSUP Dr. M. Djamil dari Mei hingga Juni 2014. Data dikumpulkan dengan cara pengisian kuisioner melalui wawancara, pencatatan hasil pemeriksaan endoskopi. Hasil penelitian didapatkan bahwa keluhan terbanyak dari pasien dispepsia adalah nyeri ulu hati $(98,15 \%)$, derajat keluhan terbanyak adalah derajat sedang $(38,89 \%)$, insiden tanda bahaya lebih banyak pada pria, faktor risiko terbanyak adalah konsumsi makanan berlemak $(92,59 \%)$, diagnosis endoskopi dispepsia terbanyak adalah gastritis $(61,11 \%)$, lokasi lesi saluran cerna atas terbanyak adalah gaster $(85,19 \%)$.
\end{abstract}

Kata kunci: dispepsia, gambaran klinis, endoskopi

\section{Abstract}

Dyspepsia is a syndrome that consist of pain or discomfort in upper abdominal, bloating, nausea, vomiting, bletching, early satiation and post-prandial fullness. One of the diagnostic tool for dyspepsia was endoscopy. It can be determined the type and the location of upper gastrointestinal's lesions in patient with dyspepsia. The objective of this study was to determined the frequency of dyspepsia's complaints, the degree of dyspepsia's complaints, the incident of alarm sign based on gender, the frequency of risk factors of dyspepsia, endoscopic diagnosis and the location of upper-gastrointestinal's lesions in patient with dyspepsia. The design of this research was an observational descriptive study. The subject of this study are consist of 54 patients with dyspepsia who have performed esophagogastroduodenoscopy (EGD) examination in Integrated Diagnostics Installation of Dr. M. Djamil Hospital Padang from May to June 2014. Data were collected by filling the questionnaire through an interview, recording the results of endoscopic examination. The results showed that the majority of dyspepsia patients' complaints were heartburn (98.15\%), the degree of complains is moderate (38.89\%), the incidence of alarm sign most experienced by male, the most risk factor of dyspepsia was the consumption of fatty foods (92.59\%), the most endoscopic diagnosis of dyspepsia was gastritis (61.11\%), and the most upper gastrointestinal lesion of dyspepsia was located in gastric (85.19\%)

Keywords: dyspepsia, clinical findings, endoscopy

Affiliasi penulis:1. Pendidikan Dokter FK UNAND (Fakultas Kedokteran Universitas Andalas Padang), 2. Bagian Penyakit Dalam FK UNAND/ RSUP Dr. M. Djamil, 3. Bagian Kimia FKUNAND Korespondensi: Citra Yuriana Putri, Email : citrayuriana@gmail.com, Telp: (0752) 626586

\section{PENDAHULUAN}

Dispepsia merupakan istilah yang digunakan untuk suatu sindrom atau kumpulan gejala/keluhan yang terdiri dari nyeri atau rasa tidak nyaman di ulu hati, kembung, mual, muntah, sendawa, rasa cepat 
kenyang, perut rasa penuh/begah. Keluhan tersebut dapat secara bergantian dirasakan pasien atau bervariasi baik dari segi jenis keluhan maupun kualitasnya. ${ }^{1}$

Lingkungan fisik seperti daerah yang padat penduduk dan sosio-ekonomi yang rendah serta negara yang sedang berkembang sering menunjang terjadinya dyspepsia. ${ }^{2}$ Sejumlah obat-obatan seperti golongan obat anti inflamasi non steroid (OAINS), aspirin, teofilin, dan beberapa antibiotik dapat menyebabkan iritasi gastrointestinal sehingga mengakibatkan dispepsia. ${ }^{1}$ Prevalensi dispepsia lebih tinggi pada wanita, pengguna obat anti-inflamasi nonsteroid, orang dengan stres psikologis, sakit kepala berulang, cemas, dan memiliki riwayat penyakit saluran cerna. ${ }^{3}$ Dispepsia juga dapat dialami oleh orang yang mengkonsumsi kafein berlebihan, minum minuman beralkohol, merokok, serta berdomisili di daerah dengan prevalensi H.pylori tinggi. ${ }^{4}$

Dispepsia memiliki tanda bahaya seperti perdarahan saluran cerna, sulit menelan, nyeri saat menelan, anemia dan penurunan berat badan lebih dari $10 \%{ }^{5}$ Studi menunjukkan bahwa pada usia lanjut terutama laki-laki yang mengalami tanda-tanda bahaya dispepsia memiliki peningkatan risiko terhadap keganasan dibandingkan dengan usia yang lebih muda. Oleh karena itu, pemeriksaan endoskopi saluran cerna atas sangat dianjurkan pada pasien usia lanjut. $^{6}$

Hasil pemeriksaan endoskopi saluran cerna atas yang sering ditemukan dari kasus dispepsia yaitu gastritis, dispepsia fungsional, gastritis erosif, dan duodenitis.Lokasi kelainan dispepsia sering ditemukan pada lambung diikuti duodenum. ${ }^{7}$ Hasil pemeriksaan endoskopi dapat ditemukan normal walaupun gejalagejala dispepsia tersebut ada. ROME III menamakan hal ini dengan istilah dispepsia fungsional. ${ }^{8}$

Hasil penelitian pada populasi umum di dunia didapatkan bahwa 15-30\% orang dewasa pernah mengalami dispepsia dalam beberapa hari. $^{3}$ Prevalensi dispepsia di negara Barat berkisar 7-41\%, tapi hanya $10-20 \%$ yang mencari pertolongan medis. ${ }^{1}$ Dispepsia mempengaruhi sekitar 25\% dari populasi Amerika Serikat setiap tahun dan hanya 5\% yang pergi ke dokter pelayanan primer. Sedangkan di Inggris prevalensi dispepsia berkisar $21 \%$ dan hanya
$2 \%$ yang berkonsultasi ke dokter pelayanan primer. $^{9}$ Hasil penelitian Khademolhosseini et al tahun 2010 pada 1978 orang di Shiraz (Iran) mendapatkan prevalensi dispepsia sekitar $29 \%{ }^{3}$

Data dari Profil Kesehatan Indonesia tahun 2007 melaporkan bahwa dispepsia menempati peringkat ke-10 untuk kategori penyakit terbanyak pasien rawat inap di rumah sakit tahun 2006 dengan jumlah pasien 34.029 orang, sedangkan di RSUP Sungailiat Kabupaten Bangka tahun 2008 melaporkan bahwa jumlah pasien dispepsia berada di urutan ke-2 terbanyak untuk pasien rawat inap dengan proporsi $6,3 \%$ dan urutan ke-3 untuk pasien rawat jalan dengan proporsi $9,9 \%{ }^{10,11}$

\section{METODE}

Penelitian dilakukan di RSUP M. Djamil Padang pada bulan Mei hingga Juni 2014. Sampel dalam penelitian ini sebanyak 54 orang. Sampel merupakan pasien yang datang ke IDT RSUP Dr. M. Djamil untuk dilakukan pemeriksaan endoskopi dan memenuhi kriteria inklusi serta tidak memiliki kriteria eksklusi. Instrumen penelitian yang digunakan adalah kuesioner dispepsia untuk menilai gambaran klinis, dan catatan hasil endoskopi untuk menilai gambaran endoskopi.

\section{HASIL}

\section{Karakteristik Subjek Penelitian}

Berdasarkan jenis kelamin, dispepsia lebih banyak pada wanita $(51,85 \%)$. Berdasarkan frekuensi umur didapatkan bahwa usia rata-rata dispepsia adalah $47.69 \pm 16.17$ tahun dandispepsia paling banyak diderita oleh usia $>40$ tahun. Berdasarkan suku bangsa didapatkan bahwa dispepsia lebih banyak pada suku Minang (87,04\%). (Tabel 1)

\section{a. Gambaran KlinisDispepsia}

Berdasarkan penelitian ditemukan bahwa keluhan dispepsia terbanyak adalah nyeri pada ulu hati $(98,15 \%)$ (Tabel 2). Derajat keluhan dispepsia terbanyak adalah derajat sedang (38,89\%) (Tabel 3). Insiden tanda bahaya lebih banyak dialami oleh pria (Tabel 4). Faktor risiko dispepsia terbanyak adalah mengkonsumsi makanan yang berlemak $(92,59 \%)$. (Tabel 5). 


\section{b. Gambaran Endoskopi}

Berdasarkan penelitian ditemukan bahwa diagnosa endoskopi dispepsia terbanyak adalah gastritis $(61,11 \%)$ (Tabel 6). Lokasi lesi saluran cerna terbanyak adalah gaster $(85,19 \%)$ (Gambar 1$)$.

TABEL

Tabel 1. Distribusi frekuensi subjek penelitian berdasarkan jenis kelamin, umur dan suku bangsa

\begin{tabular}{lcc}
\hline Karakteristik Subjek & $\mathbf{n}$ & $\%$ \\
\hline Jenis kelamin & 26 & 48,15 \\
Pria & 28 & 51,85 \\
Wanita & & \\
Umur (tahun) & 4 & 7,41 \\
$<20$ & 5 & 9,26 \\
$21-30$ & 7 & 12,96 \\
$31-40$ & 14 & 25,93 \\
$41-50$ & 11 & 20,37 \\
$51-60$ & 13 & 24,07 \\
$>60$ & & 87,04 \\
Suku bangsa & 47 & 12,96 \\
Minang & 7 & \\
Non Minang &
\end{tabular}

Tabel 2. Distribusi frekuensi keluhan dispepsia

\begin{tabular}{lcc}
\hline \multicolumn{1}{c}{ Keluhan } & $\mathbf{n}$ & $\%$ \\
\hline Nyeri ulu hati & 53 & 98,15 \\
Kembung & 41 & 75,93 \\
Mual & 50 & 92,59 \\
Muntah & 20 & 37,04 \\
Cepat kenyang & 24 & 44,44 \\
Sendawa & 50 & 92,59 \\
\hline
\end{tabular}

Tabel 3. Distribusi frekuensi derajat keluhan dispepsia

\begin{tabular}{lcc}
\hline $\begin{array}{c}\text { Derajat Keluhan } \\
\text { Dispepsia }\end{array}$ & $\mathbf{n}$ & $\%$ \\
\hline Ringan & 15 & 27,78 \\
Sedang & 21 & 38,89 \\
Berat & 18 & 33,33 \\
\hline Total & $\mathbf{5 4}$ & $\mathbf{1 0 0}$ \\
\hline
\end{tabular}

Tabel 4. Distribusi frekuensi insiden tanda bahaya pasien dispepsia berdasarkan jenis kelamin

\begin{tabular}{lcc}
\hline \multirow{2}{*}{ Jenis Kelamin } & \multicolumn{2}{c}{ Tanda Bahaya } \\
\cline { 2 - 3 } & $\mathrm{n}(\%)$ & $\mathrm{n}(\%)$ \\
\hline Pria & $12(22,22)$ & $14(25,93)$ \\
Wanita & $6(11,11)$ & $22(40,74)$ \\
\hline Total & $18(33,33)$ & $36(66,67)$ \\
\hline
\end{tabular}

Tabel 5. Distribusi frekuensi faktor risiko dispepsia

\begin{tabular}{lcc}
\hline Faktor Risiko Dispepsia & $\mathbf{n}$ & $\%$ \\
\hline Konsumsi makanan pedas & 44 & 81,48 \\
Konsumsi makanan & 50 & 92,59 \\
berlemak & & \\
Kopi & 15 & 27,78 \\
OAINS & 25 & 46,30 \\
Alkohol & 2 & 3,70 \\
Merokok & 17 & 31,48 \\
\hline
\end{tabular}

Tabel 6. Distribusi frekuensi diagnosis endoskopi pasien dispepsia

\begin{tabular}{lcc}
\hline \multicolumn{1}{c}{ Diagnosis } & $\mathbf{n}$ & $\%$ \\
\hline Gastritis & 33 & 61,11 \\
Bile reflux gastritis & 4 & 7,41 \\
Gastropati & 2 & 3,70 \\
Ulkus gaster & 13 & 24,07 \\
Ulkus duodenum & 3 & 5,56 \\
Polip duodenum & 1 & 1,85 \\
Normal/dispepsia & 3 & 5,56 \\
fungsional & & \\
\hline
\end{tabular}

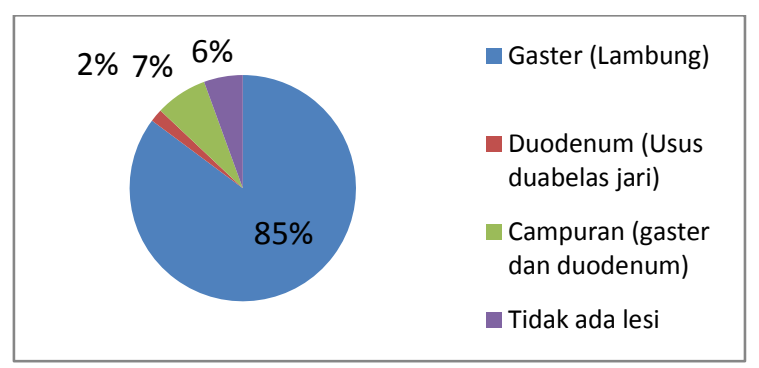

Gambar 1. Distribusi frekuensi lokasi lesi saluran cerna atas pasien dispepsia 
Berdasarkan hasil penelitian, didapatkan penderita dispepsia lebih banyak pada wanita. Hal ini sesuai dengan penelitian Khademolhosseini et al pada tahun 2010 dan Yazdanpanah et al pada tahun 2012 yang melaporkan bahwa prevalensi dispepsia lebih tinggi pada jenis kelamin wanita. ${ }^{3,12}$

\section{PEMBAHASAN}

Usia rata-rata subjek dalam penelitian ini adalah $47.69 \pm 16.17$ tahun dengan kelompok usia terbanyak adalah kelompok usia $>40$ tahun. Hal ini sesuai dengan Shah et al pada tahun 2001 dan Yazdanpanah et al pada tahun 2012 yang melaporkan bahwa prevalensi dispepsia di India dan Irak lebih banyak pada kelompok usia $>40$ tahun. $^{12,13} \mathrm{Hal}$ ini disebabkan oleh tingginya faktor agresif dan rendahnya faktor defensif saluran cerna pada kelompok tersebut. Faktor agresif yang paling banyak pada kelompok usia $>40$ tahun yaitu riwayat mengkonsumsi obat-obatan seperti OAINS dan aspirin, sedangkan faktor defensif yang menurun ialah lapisan mukosa lambung, prostaglandin dan sekresi bikarbonat mukosa lambung.

Suku bangsa subjek dalam penelitian ini adalah sebagian besar suku Minang. Hal ini dikarenakan jumlah penduduk suku Minang yang lebih dominan di Sumatera Barat dibandingkan suku lain.

Pada Tabel 2 didapatkan bahwa 98,15\% pasien dispepsia memiliki keluhan nyeri pada ulu hati. Hasil ini sesuai dengan penelitian Erivanti tahun 2008, Annisa tahun 2009 dan Susilawati tahun 2013 yang melaporkan bahwa keluhan terbanyak pasien dispepsia adalah nyeri ulu hati. ${ }^{14-16}$ Makmun pada tahun 2005 menyebutkan bahwa nyeri ulu hati merupakan keluhan dispepsia yang paling sering menjadi alasan utama untuk berobat ke ahli gastroenterologi dan penyebab bagi seseorang untuk tidak bekerja. ${ }^{17}$ Dalam penelitian Noerhidajati tahun 2010 ditemukan $81,5 \%$ penderita dispepsia yang datang ke poli dengan keluhan nyeri sedang dan $13,9 \%$ dengan nyeri berat. ${ }^{18}$

Pada Tabel 3 didapatkan bahwa 38,89\% dar pasien dispepsia memiliki derajat keluhan sedang. Berarti aktivitas sehari-hari pasien sudah mulai terganggu akibat gejala dispepsia. Mudjaddid tahun 2005 dan Kumar et al tahun 2012 mengemukakan bahwa nyeri abdomen yang diderita oleh pasien dispepsia sangat mengganggu kegiatan sehari-hari sehingga angka bolos kerja menjadi tinggi, produktivitas menurun dan kualitas hidup menurun akibat meningkatnya angka kecemasan dan depresi pada pasien dispepsia. ${ }^{8,19}$

Pada Tabel 4didapatkan bahwa insiden tanda bahaya lebih banyak dialami oleh pria $(22,22 \%)$. Studi menunjukkan bahwa pasien dispepsia usia lanjut terutama laki-laki yang mengalami tanda-tanda bahaya memiliki peningkatan risiko terhadap keganasan saluran cerna dibanding usia yang lebih muda. Oleh karena itu, pemeriksaan endoskopi saluran cerna atas sangat dianjurkan pada pasien pria usia lanjut. ${ }^{6}$

Pada Tabel 5 didapatkan bahwa faktor risiko dispepsia yang paling banyak adalah konsumsi makanan berlemak (92,59\%) diikuti oleh konsumsi makanan pedas $(81,48 \%)$. Hal ini berhubungan dengan suku bangsa responden yang sebagian besar adalah orang Minang dan Melayu yang gemar mengkonsumsi makanan pedas dan berlemak.

Lemak merupakan salah satu faktor terpenting yang mempengaruhi pengosongan lambung. Apabila di duodenum sudah terdapat lemak, pengosongan isi lambung yang berlemak lebih lanjut ke dalam duodenum ditunda sampai usus halus selesai mengolah lemak yang sudah ada di usus tersebut. ${ }^{20}$ Makanan berlemak seperti keju, gorengan merupakan makanan yang lama di cerna atau sulit dicerna menyebabkan hipersekresi cairan lambung dan menimbulkan nyeri pada lambung. ${ }^{21}$

Pada Tabel 6 didapatkan bahwa diagnosis endoskopi pasien dispepsia yang paling banyak adalah gastritis $(61,11 \%)$. Penelitian sebelumnya menyebutkan bahwa dari kasus-kasus dispepsia yang dilakukan pemeriksaan endoskopi, kelainan yang sering didapatkan adalah gastritis. ${ }^{7,22} \mathrm{Hal}$ ini berkaitan dengan derajat keluhan dispepsia dalam penelitian ini yang sebagian besar derajat sedang. Laksono tahun 2011 melaporkan bahwa terdapat hubungan antara skor dispepsia dengan tingkat kerusakan mukosa lambung yang dinilai secara endoskopi. ${ }^{22}$

Berdasarkan Gambar 1 didapatkan bahwa 85,19\% dari lesi saluran cerna atas pasien dispepsia berlokasi di gaster. Hasil penelitian ini sesuai dengan 
penelitian Makmun tahun 2005 yang menyatakan bahwa lesi mukosa pada gaster memiliki prevalensi tinggi sekitar 50 hingga $70 \% .^{17}$ Dalam penelitian ini, diagnosis endoskopi dispepsia terbanyak adalah gastritis, maka dari itu lokasi lesi terbanyak adalah gaster.

\section{DAFTAR PUSTAKA}

1. Djojoningrat D. Dispepsia fungsional. Dalam: Sudoyo AW, Setiyohadi B, Alwi I, Simadibrata M, Setiati S, editor (penyunting). Buku Ajar IImu Penyakit Dalam. Edisi Ke-5. Jakarta: Internal Publishing; 2009. hlm.529-33.

2. Sosrosumihardjo DR. Pendekatan diagnosis laboratorium penyakit yang disebabkan helicobacter pylori. Majalah Kedokteran Indonesia. 2004;54:23-27.

3. Khademolhosseini F, Mehrabani D, Zare N, Heydari ST, Behesti M, Saberi MF. Prevalence of dyspepsia and its correlation with demographic factors and lifestyle in Shiraz, Southern Iran. Middle East Journal of Digestive Disease. 2010; 2:24-30.

4. Abdullah M, Jeffri G. Dispepsia. CDK-197. 2012; 39:647-51.

5. Lacy BE, Talley NJ, Camilleri M. Functional dyspepsia: time to change trial design. American Journal Gastroenterology. 2010;105:2525-9.

6. Travis AC, Daniel P, John RS. Endoscopy in the Elderly. American Journal Gastroenterology. 2012; 107:1495-501.

7. Simadibrata MK. Pemeriksaan Endoskopi Saluran Cerna. Dalam: Sudoyo AW, Setiyohadi B, Alwi I, Simadibrata M, Setiati $S$, editor (penyunting). Buku Ajar IImu Penyakit Dalam. Edisi Ke-5. Jakarta: Internal Publishing; 2009. hlm 467-73.

8. Kumar A, Patel J, Sawant P. Epidemiology of Functional Dyspepsia. Supplement To Japi. 2012; 60:9-12.

9. Hu WHC, Wong WM, Lam CLK, Lam KF, Hui WM, Lai KC. Anxiety but not depression determines health care-seeking behaviourin Chinese syndrome: a population-based study. Aliment Pharmacol Ther. 2002;16:2081-8.

10. Depkes RI. Profil Kesehatan Indonesia. Jakarta: Departemen Kesehatan Republik Indonesia; 2007.
11.RSUD Sungailiat Bangka. Jumlah penyakit terbanyak ranap dan rajal di RSUD Sungailiat tahun 2008 (diunduh 22 April 2014). Tersedia dari: URL: HYPERLINK http://www.bangka.go.id/ content.php?id content=rsud

12. Yazdanpanah K, Moghimi N, Yousefinejad V, Ghaderi E, Azizi A, Nazem SF. Dyspepsia prevalence in general population aged over 20 in the West Part of Iran. J Pak Med Ass. 2012; 62:672-6.

13. Shah SS, Bhatia SJ, Mistry FP. Epidemiology of dyspepsia in the general population in Mumbai. Indian Journal Gastroenterol. 2001;20:103-6.

14. Erivanti M. Faktor yang berhubungan dengan kejadian sindroma dispepsia pada supir truk di PT. Varia Usaha (skripsi). Surabaya: Universitas Airlangga; 2008.

15. Annisa. Hubungan ketidakteraturan makan dengan sindrom dispepsia remaja perempuan di SMA Plus Al Azhar Medan (skripsi). Medan: Universitas Sumatera Utara; 2009.

16. Susilawati. Hubungan pola makan dengan kejadian sindroma dispepsia fungsional pada remaja di Madrasah Aliyah Negeri Model Manado (skripsi). Manado: Universitas Sam Ratulangi; 2013.

17. Makmun D. Pendekatan klinik nyeri perut. Dalam: Rani AA, Manan C, Djojoningrat D, Kolopaking MS, Makmun D, Abdullah M. et al, editor (penyunting). Dispepsia Sains \& Aplikasi Klinik. Edisi ke-2. Divisi Gastroenterologi Departemen IImu Penyakit Dalam FKUI; 2005. hlm.87-94.

18. Noerhidajati E, Izzudin, Djagat HP. Faktor-faktor yang berhubungan dengan amplifikasi somatosensori pada penderita dengan keluhan nyeri ulu hati. Sains Medika. 2010;2:178-92.

19. Mudjaddid E. Peran psikopatologi pada sindrom kolon iritabel: seberapa penting? Dalam: Simadibrata $M$, Syam AF, editor (penyunting). Update In Gastroenterology 2005. Pusat Informasi dan Penerbitan Departemen IImu Penyakit Dalam Fakultas Kedokteran Universitas Indonesia; 2005.hlm.54-64.

20. Sherwood L. Fisiologi manusia dari sel ke sistem. Edisi ke-2. (terjemahan). Jakarta: EGC;2001.

21. Salma. Pencegahan dan perawatan perut kembung. (diunduh 20 Agustus 2014). Tersedia 
dari: URL: HYPERLINK: http://majalahkesehatan. com/pencegahan-dan-perawatan-perut-kembung/

22. Laksono RD. Hubungan skor keparahan dispepsia dengan tingkat kerusakan mukosa lambung secara endoskopi (tesis). Medan: Universitas Sumatera Utara; 2011. 